\title{
Oxighat Axticles.
}

\section{SEXUAL PERVERSION OR VICE? A PATHO- LOGICAL AND THERAPEUTIC INQUIRY."}

BY MORTON PRINCE, M.D.,

Instructor iu Diseases of the Nervons System, Hat vard Medical school.

It is not necessary for me before a society of experts in psychiatry to dwell upon the medical, social and forensic importance of sexual perversion. Nor need I, for the purposes of this paper, more than mention the different ways in which the sexual instinct may be perverted. It may be excited by, and therefore lead to acts of cruelty or violence inflicted upon, the opposite sex (Sadism), or by the opposite state, the passive suffering of pain which has been inflicted by the opposite sex (Masochism), or it may be excited by certain objects, whether a part of the female body or dress, or other objects (Fetichism).

Perversion may further take the form of homo-sexuality, that is, the substitution or co-existence of sexual feeling for the same sex in place of, or by the side of, that for the opposite sex. This is also known as contrary sexual instinct, or sexual inzersion. These different forms of perversion have also been classed as varieties of sexual paræsthesia.

The object of this paper is not to present any new facts or new theories of these aberrations, but rather to re-examine the grounds on which the later and dominating views of the nature of these so-called perversions are based, with a view of ascertaining whether these views are really well founded, and whether, after all; the facts

'Read before the Medico-Psychological Society, Jan. 27th, 1898 . This paper is largely based on the article on "Sexual Psychoses" by the writer in vol. iv. of the Amer. Syst. of Practical Medicine, now in press. 
upon which they are supposed to rest have been so well proven that we are justified in accepting the prevailing doctrine. Further, it may be inquired whether the common acceptance of those views which marks most of the contemporary literature is not due to the influence of personal authority rather than a careful consideration of the facts. We may also inquire whether, by taking a broader view of these anomalies, we may not class them with many well-recognized non-sexual manifestations of hysteria. neurasthenia. or other forms of nervous degeneration, and find a common method of treatment.

As the time limit of such a paper does not admit of a separate study of each of the perversities, I shall limit myself, for the most part, to an examination of the one which is most frequent and has received the widest discussion, namely, contrary sexuality, prefacing this special inquiry by a few general remarks on the perversities as a whole.

The first important question is: How far are these perversions the necessary expression of a clisordered nervous system, and how far do they represent merely indulgences in vice and cultivated habits? So far as they are simply. vicious habits, they can only be regarded as pericrsity. not periersion; that is, as vice, not disease. This view is not altered even in the case of inclividuals who have degenerate or in other ways diseased nervous systems, provided that they have cultivated the habits. and that the habits are the direct result of such cultivation. A paranoiac or an imbecile may cultivate vice as well as sound-minded people. Degenerate people may not be morally or legally responsible; but this inquiry is not one of responsibility, but of genesis. What is the origin of and what influences have developed the sexual aberrations? If these are the manifestation of a diseased nervous system, in the same sense as hysteria is the manifestation of a neuropathic condition. then these sexual phenomena are true perversions and pathological. 
On the other hand-this point may further be insisted upon, in addition to what has just been said-the presence of a psychopathy does not necessarily indicate that the sexual habits are not vice. A person who, let us say, has by inheritance received a neuropathic constitution, or even exhibits weakmindedness or some form of insanity, is no less subject to the same influences as are normal individuals. His nervous system is equally open to education; so that feelings, tastes and habits can be cultivated in the one as in the other. But it cannot necessarily be inferred from the co-existence of such habits and a psychopathy that the former is the symptomatic manifestation of the latter. Hysterics, degenerates and imbeciles have less intellectual power for resisting feelings and external influences than healthy people. Their judgments are warped, and they do not normally foresee the consequences of their actions, or, if they do, they are not influenced thereby in their conduct. They may not have a normal power of self-control, of restraining impulses. From this lack of resisting power they are more likely to submit to external influences and cultivate the gratification of their senses; that.is, they are more likely to be the victims of vice than normal persons. But a diminished resisting power does not make the thing to be resisted pathological; for this other conditions are necessary.

The power of resistance is a force of varying quantity in different individuals, and the difference between the resisting power of a normal individual and a diseased one is only one of degree, and may be small. ${ }^{2}$ Nevertheless, though such diseased persons are more likely to exhibit vice than liealthy people, it is, a priori, possible that what would be vice in others may be only a pathological phenomenon in them. Feelings and actions may be only

'What degree of lack of resisting power constitutes irresponsibility is still another question, and a distinct one, of an entirely different nature, which does not change the nature of an act, otherwise vicious, but may affect the culpability. 
pathological and necessary reactions of a diseased nervous system to external influences. A careful inquiry is, therefore, essential to determine which of these conditions obtains.

These observations are here made, because there is considerable and important difference of opinion regarding the pathology and nature of these sexual aberrations, and, as it seems to the writer, much confusion of thought regarding their relation to disease and vice.

There are two views regarding the nature of perversion which are radically opposed, and which, from a social and therapeutic point of view, have respectively important consequences. The one leads to therapeutic nihilism and social hopelessness; the other offers hope and possibilities.

The theory that has been most widely accepted by writers on the subject is that sexual perversion has its basis in a diseased nervous system, which, in most cases, is the result of inheritance. $\Lambda$ psychopathic or neuropathic groundwork is in almost all cases essential, but the perverse phenomenon arises spontaneously, without external cause. Its origin is, therefore, entirely independent of cultivation by vicious habits, education or seduction. In some instances it is equally maintained that these perversions are acquired as the result of cultivation, with or without the co-operation of an inherited neuropathic condition. But it would seen that, with the exception of fetichism, which is always acquired. according to this school, the acquired cases are a distinct minority. In most cases nascitur, non fit.

"This perverse sexuality," says von Krafft-Eling, speaking of the contrary sexual instinct, "appears spontaneously, without external cause. with the development of sexual life, as an individual manifestation of an abnormal form of the vita sexualis, and then has the form of a congenital phenomenon; or it develops upon a sexuality. the beginning of which was normal, as a result of any definite injurious influences, and then appears as an acquired 
anomaly. . . . Careful examination of the so-called acquired cases makes it probable that the predisposition also present here consists of a latent homo-sexuality, or, at least, bi-sexuality. which, for its manifestation, requires the influence of accidental causes to rouse it from its slumber." 3 While objections may be male to this theory when applied to homo-sexuality, as has been done with great force by von Schrenck-Notzing, ${ }^{4}$ the theory has consideralle strength when we seek for an explanation of Sadism and Masochism. Between the homo-sexual influences and the sadistic influences, which lead to murder and mutilation of the victim's body, there is a wide gulf, and we should not necessarily expect a similar pathological condition as a basis of both. As to Sadism, von Krafft-Ebing expresses the opinion that, "as a rule, it may be safely assumed that the psychopathic state (perverse instinct) exists ab origine."

"Sadism is, then, nothing else than an excessive and monstrous pathological intensification of phenomenapossible, too, in normal conditions in rudimentary formswhich accompany the psychical vita sexualis, particularly in males." The same writer lays stress on the weakness or absence of all restraining ideas in the psychopath who gives free hand to the development and expression of the congenital perversion. But he neglects the influence which a deliberate cultivation may have upon a mild impulse or sensory association at the beginning. If Sadism is an "excessive and monstrous intensification of phenomena" existing "in a rudimentary form" in normal individuals, then the perversion is the intensification. and

".Psychopathia Sexualis" (p. 187), translated by Charles Gilbert Chaddock, M. D., I893. See also "Zur Erklärung der conträren Sexualempfindung," Jahrbücher für Psychiatrie und Neurologie. 1895, by the same writer.

".'Suggestive Therapeutics in Psychopathia Sexualis." Translated by Charies Gilbert Chaddock. 1895.

.. '. Psychopathia Sexualis," p. 60. 
the question is, To what is this intensification due? Does it exists, $a b$ origine, in its intense form as a result of pathological development, or is it a later disease symptom, or is the intensification due to cultivation by a morally clepraved and mentally weakened individual? Or. may it be due to two or more of these factors? The autobiographies and histories of cases found in the literature do not allow of the first interpretation. It is possible that certain anomalous sensory associations may be the starting point of such perversion, and cultivation does the rest. For example, the case was brought to my attention of a perfectly healthy, mentally and physically. medical man who was sexually excited by the sight of a surgical operation. This person is a typically strong and healthyminded man. Suppose him to have been a mental degenerate; how easy it would have been for him to cultivate sadistic impulses. The origin of sadistic impulses is of less practical importance than is that of contrary sexuality, as most of the individuals who exhibit then are otherwise psychopathic (e. g.. imbeciles, degenerates or insane), though the question is of some importance forensically as bearing on the question of responsibility.

Von Krafft-Ebing's" work being almost the first to treat systematically the subject of sexual perversion, and presenting the matter with great erudition. has been very widely drawn upon by subsequent writers. The interpretation of these aberrations given by the author has very profoundly influenced medical opinion, and has been quite extensively accepted. This work was soon followed by a publication on the contrary sexual instinct by A. Moll, ${ }^{7}$ who also adopted the congenital theory, originally proposed, it is true. ly Casper, ${ }^{8}$ in 1852 . Quite a large num-

-According to von Krafft-Ebing, the most important previous writings were those of Moreau ("Des aberrations du sens générique") and Tarnowski ("Die krankhaften Erscheinungen des Geschlechtssinnes.").

7 . Die conträre Sexualempfindung." Berlin, I891.

"Westphall adopted the congenital theory for contrary sexuality. 
ber of contributions to the subject, with reports of numerous cases of different kinds of perversion, have appeared since von Krafft-Ebing's work. In America, Kiernan, Chaddock and Lydston have advocated the congenital theory. More lately, a strong protest against these views has appeared in the work of von Schrenck-Notzing. ${ }^{\circ}$ This author, in opposition to the opinion of the writers just cited and of others. has urged with great force that sexual perversion, instead of being an original psychopathy, is a cultivated instinct. Heredity and a neuropathic constitution play an important part, but this part is only that of weakened power of resistance to external infuences. The contrary sexual instinct is, as such, not inherited, nor is it congenital any more than are the majority of psychoses, but only that tainted or degenerated nervous system, in consequence of which the individual offers a mental weakness, a lack of resistive power to external influences and a lack of control over desires, however excited. By a process of cultivation the neuropath develops feelings and gives them expression in outward acts, over which he sooner or later may lose all control. The first awakening of the perverse instinct may be entirely fortuitous, or by auto-suggestion, or it may be seduction, or other accidental external circumstances; from this time on it is a process of education. Von Schrenck-Notzing would explain in this way the origin of all forms of sexual perversion, although in the exposition of his theory his argument is clevoted almost entirely to the contrary sexual instinct.

The influence of von Krafft-Ebing's able exposition of the subject, as just said, has colored much of the writings of others. But I think the conviction must be forced upon the careful student of these writings that the attempt to make vicious habits the result of congenital anomalies has been based upon evidence that, from its very nature. must be incomplete and unreliable.

- "Suggestive Therapeutics in Psychopathia Sexualis." Translated by Charles Gilbert Chaddock, M. D., 1895. 
In support of this statement let us consider briefly, but with more particularity, the pathogenesis of contrary sexuality, in accordance with the design mentioned at the outset.

This aberration, as has been said, consists, in the existence of sexual feeling for the same sex, co-existing in its fully developed form, with entire absence of sexual feeling for the opposite sex. In the more moderate form there may still be inclination toward the opposite sex, but in the higher degrees of the perversion there may be a feeling of actual repulsion for the opposite sex, while the whole psychical personality, the tastes, feelings and modes of thought of the individual may become changed to correspond with the sexual perversion; that is, the character of the male becomes feminine, and vice versa. Now, the thesis is that all this change of character, psychical as well as sexual, is not only congenital, but a partial manifestation of a neuropsychopathic state, in most cases hereditary. Hence it is in no sense a perversity or vice, but a true anomaly or perversion of instinct, in the sense that it is the product of mal-development, in the same way that any of the normal instincts, tastes or sensory functions are the product of normal development. In other words, with "a normal anatomical and physiological state of the (genital) organs a sexual instinct may be developed which is the exact opposite of that characteristic of the sex to which the individual belongs." It appears spontaneously, without external cause, with the development of sexual life.

Various theories have been proposed, many of them fanciful, to account for the development of this (according to this view) anomalous condition. But, as all these theories presuppose the congenital character of the anomaly, a serious consideration of them is hardly in order until the phenomenon has been proved to be congenital.

Nevertheless, a brief statement of some of their theories makes the point of view of these writers more 
definite. Ulrichs. himself a pervert, thought that a female mind was inclosed in a male body; that is, that there were people, to whom he gave the name of "Urnings," whose bodily structure was that of a man, whose sexual instincts were those of a woman. He also considered this condition due to atavism.

This same idea has been put in a more taking form by Kiernan, ${ }^{10}$ who rests it upon the biological facts that bisexuality, or hermaphroditism, is found in the lowest orders of life, and that in the human embryo this same bisexuality exists up to a certain age. In degenerates there is a "throwing back," to use the language of the kennel, to this primitive embryological form, to the extent that. while in the adult male there is a differentiation of anatomical form (sexual organs), the nervous system is developed on the female type. To quote his language. "The original bi-sexuality of the ancestors of the race, shown in the rudimentary female organs of the males, could not fail to occasion functional, if not organic, reversion, when mental or physical manifestations were interfered with by disease or congenital defect." Again,. . . . "It seems certain that a femininely functionating brain can occupy a male body, and vice versa."

The lowest animals are bi-sexual, and the various types of hermaphroditism are more or less complete reversions to the ancestral type. Lydston ${ }^{11}$ advocates the same hypothesis, which is meant to be the principle of atavism. I say, meant to be, for it seems, oddly enough, to have been overlooked that there is very little atavism about it. If there was a development of a female anatomical structure we might talk of "throwing back," but when the anomaly consists, as it does, of psychical phenomena and nervous reflexes, it is difficult to see how there can be a reversion to or inheritance of a nervous system which never had any

10 Med. Standard. Nov., 1888.

"Med. and Surg. Reporter. Sept., 1889. 
existence in the lower order of life, and never came into existence until the present mono-sexual being was evolved. It is only fair to state that credit may be given, if credit is desired.to one of v.Krafft-Ebing's patients, by whom this theory.was proposed.

Chevalier has proposed a modification of this theory in this wise: Originally, in the embryo, man is bisexual; in the future development there is a sort of contest, in which one or the other factor, male or female, develops at the expense of the other, with the result of a mono-sexual individual. But traces of the other sexuality remain. Under certain conditions these latent sexual characteristics successfully succeed in developing themselves, and contrary sexuality results.

Magnan and Gley also imagine a female brain in a male bodly.

In all these expositions there is a naive assumption that in the brain of either sex there is a sort of nervous mechanism, peculiar to either sex, and corresponding to the difference in anatomical form-a hazy sort of cerebral localization involving a different cerebral architecture for each sex. This seems to me nothing more nor less than the old-fashioned phrenology, and difficult to reconcile with the first principles of psychology.

Westphal, who first gave the name contrary sexuality, thought the condition was congenital, but refrained from hypothesis, excepting that in one case, in which there were olfactory hallucinations, he thought this particular phenomenon was atavistic. from the lower animals. Westphal, who also regarded the condition as a psychosis, gave the impetus to the publication of a long list of cases by other writers.

The best congenital hypothesis is undoubtedly that of von Krafft-Eling, who thinks that an explanation "may perhaps be found in the fact that it represents a peculiarity bred in descendents, but arising in ancestry: The hereditary factor might be an acquired abnormal inclination for 
the same sex in the ancestors, which, being transmitted. becomes fixed as a congenital, abnormal manifestation in the descendents." .

Kiernan had also suggested this possibility for certain cases.

On the other hand, Binet considers that the whole perversion is acquired through the force of the law of. association of ideas.

Among the names of those contributing to the subject are to be found many of well-known writers in neurology and psychiatry. But the most important contributions are those already mentioned, and particularly the works of Moll, ${ }^{12}$ von Krafft-Ebing ${ }^{13}$ and von SchrenckNotzing. ${ }^{14}$ The difference in the views of these writers has already been pointed out. Besides the fact that the manifestations of contrary sexuality are acquired, von Schrenck-Notzing holds that nevertheless these manifestations become in time imperative sensations and imperative ideas, and thus from this point of view may be looked upon as psychoses-artificially created in a neuropathic soil in most instances. This opens a very wide field for discussion, as it is no easy matter to settle what decisive element constitutes an imperative idea. The familiar language of the pervert, which is stereotyped in "irresistible impulse," too often should be written. "I don't want to."15 Still, we must allow, as we see in the alcoholic and opium habit, that for weakened resisting powers sensations may be well educated to such an extent as to become imperative.

12 "Conträre Sexualempfindung."

"s "Psychopathie Sexualis" and "Zur Erkiärung der conträren Sexualempfindung."

" "Suggestive Therapeutics in Psychopathia Sexualis."

is "I wish to state expressly that, though I am conscious of the abnormality of my inclinations, I have no desire to change them; I long only for a time when more easily, and with less danger of discovery, I can give rein to $m y$ desires and experience a delight that will harm no one."-Autobiography; case 149 , v. K.-E. 
Now, putting aside hypotheses of the "how," an examination of the congenital perversion theory shows that it rests entirely upon the autobiographies of perverts. and certain assumptions (to be presently mentioned) regarding the normal development of the vita sexualis, and of the tastes, habits and nodes of thought peculiar to each sex.

It is believed that a person is capable of remembering all the circumstances attending the gradual growth of the sexual functions in early childhood, has a distinct recollection of the causes which first called it forth, and that a failure to remember possible excitants is equivalent to their non-existence. A reliance upon evidence of this kind in any other department of human knowledge, whether medical or non-medical, I am sure, would only excite surprise. Even in taking an ordinary medical history, we should hesitate to accept such testimony as final, and I think we should be even more cautious in our examination of autobiographies which attempt to give an analysis, founded on introspection, of the feelings, passions and tastes of degenerate individuals who attempt to explain their first beginnings in early childhood, and attribute each to its proper excitant. As von Schrenck-Notzing has pointed out, in his very careful study of the published cases, very few of these autobiographies will stand analysis. Probably there is no class of people whose statements will less stand the test of a searching cross-examination than the moral pervert. One cannot help feeling that if the pervert was thus examined by an independent observer, instead of being allowed to tell his own story without interruption, a different tale would be told, or great gaps would be found, which are now nicely bridged, or many asserted facts would be resolved into pure inferences.

Taking one point alone, it is extremely doubtful whether any one can remember the first beginnings of the vita sexualis. He may remember certain occasions, which, from the special intensity of the excitation, or from peculiar associations, persist as vivid mental pictures; just 
as we remember certain pleasurable experiences of boyhood connected with sports, but not all nor the first.

The second error of those who maintain the congenital theory is that they overlook the influence which casual external circumstances have in suggesting feelings and ideas to the mind, and in directing thoughts which appear to be spontaneous. ${ }^{16}$ These external circumstances may be trivial or not, and may be forgotten. Even when very: prominent for the moment in consciousnes, they may be forgotten, while the effects may persist. The enlargement of our knowledge of the substrata of consciousness, and the after-influence of such subconscious states upon the personality of the individual, has made it possible for us to understand the genesis of certain neuroses which before were inexplicable. Janet has demonstrated this influence in the production of some of the manifestations of hysteria. With this knowledge it is next to impossible to say that sexual aberrations were not originally suggested by external conditions in individual cases, or the product of auto-suggestion. ${ }^{17}$ A very suggestive example of the influence of this kind upon the lower strata of consciousness in producing psychoses is the following, from the writer's own experience: A young girl, about 16 years old, was pursued with an uncontrollable fear of vomiting. As a matter of fact, she never did vomit, but the fear was so. intense that she was unwilling to leave the house alone, or,

${ }^{10}$ Whether or not a neuropathic taint is necessary, as has been maintained, is a secondary nuatter. The existence of an hereditary taint has, however, bcen sometimes accepted on insufficient evidence.

${ }^{17}$ A capital illustration of the influence of forgotten causes in producing physical phenomena is the following: A lady told me of a dream, in which she saw distinctly the face of a person whom she had never secn. Her description of the person being very accurate, I insisted, to test the matter, that she must have seen or heard of the person before. On assuring me of the impossibility of this, I told her, as was the fact, that a few days previously I had described this person to her, using the same language that she now used for the same description. She had no recollection of it. Sexual suggestions and excitants might be similarly forgotten. 
for that matter, even when accompanied, go in places of amusement. or to such distances from home that she could not quickly reach her house. The fear, although always present, was subject to exacerbations. In such attacks her suffering was very great and the mental state uncontrollable. She would take off her clothes, and run up and down the room, crying and begging her mother not to let her vomit. This fear had apparently developed spontaneously during early girlhood, and might easily have been considered congenital if the original history, as given by the patient herself and mother, had been believecl. But from the mother, after persistent inquiry, $I$ obtained the following history, till that moment forgotten: When the patient was a child, say, 5 years old, her sister was taken ill with scarlet fever, the first symptom of which was violent vomiting. That the other child (my patient) might be prevented from catching the disease, she was told that if she went near her sister she would be taken with romiting in the same way. This had the desired effect. but when the sister recovered it was with some difficulty that my patient could be induced to come into her presence. She ran away and hid in a closet, exhibiting considerable fear. It is reasonable to suppose that the impression made upon the mind at that time had left a subconscious idea, which was the cause of the apparently motiveless fear later exhibited. The patient had no memory of all this. The excitation of abnormal sexual feelings may well have similar external causes long since forgotten.

The third error of this school is that it assumes that normally there is a hard and sharp line drawn by nature between the normal personalities of the sexes. As a matter of fact, sharp lines of demarcation do not occur any more than in the length of the nose or size of the hand. Taking a large number of people, the male personality normally shades into the female, and vice versa. What I mean to say is that, taking a large number of normal males and an equal number of normal females, we might 
place them in a row, so that at one end would come the males with strong, vigorous, masculine characters; in the micklle, but at the extreme end of the male line, the men with female personalities; adjoining these the masculine females, differing but slightly except in anatomical form from the males; while at the extreme end of the female line would come those with strongly marked feminine personalities.

Fourthly, the effect of education, meaning by this the total environment, intentional education, unconscious mimicry, external suggestion, example, etc., etc.-the effect of this, I repeat, in moulding the tastes and habits of thought and manners of the child, and thus differentiating those of one sex from those of the other, has been overlooked.

I think it is extremely probable that if a boy were brought up as a girl and a girl as a boy, and absolutely freed from all counter influences, such as the unconscious influence of public criticism, etc., each would have the non-sexual tastes and manners of the other sex.

Fifthly, it is questionable whether only abnormally the vita sexualis of the male is excited by the Mmale, and conversely. There is every reason to believe that in some perfectly healthy individluals some degree of erotic feeling or idleas may be excited by the sight or touch of the form of a person of the same sex, and, at any rate, thoughts (pertaining to anatomy) so excited may very naturally awaken secondarily associated sexual feelings. For instance, the vita sexualis in a boy is first associated with his own sexual organs. Later, the sight of those of another boy awakens the association of ideas by the wellknown law, and then, in a degenerate, cultivation does the rest. Von Krafft-Ebing's first case (I06) of a girl with hyperesthesia sexualis and homo-sexuality is readily explainable in this way. As von Krafft-Ebing points out, in the beginning of sexual development in the child "the psychical relation to persons of the opposite sex is still 
absolutely wanting, and the sexual acts cluring this period partake more or less of a reflex spinal nature." "With the inception of anatomical and functional development of the generative organs, and the differentiation of form belonging to each sex, which goes hand in hand with it in the boy or girl, rucliments of a mental feeling corresponding with the sex are developed, and in this, of cours:. education and external influences in general have a powerful effect upon the individual, who is now all attention." Now, in a person of perfectly healthy mind and body, all social customs, habits of thought, unwritten laws, and moral precepts tend to suppress any existing homosexual feeling and its gratification, and to encourage hetero-sexual fecling. On the other hand, the person of tainted constin ntion does everything in his power to foste: indulge and cultivate the perverse instinct, while in such a soil the feelings themselves acquire monstrous force. That the future development of this perversity is due to cultivation there is no gluestion. We have only to reacl the autoliographies to be convinced of it. Thus may arise a perversity that had its origin in a normal reflex. but the acciclental cause of which is forgotten with much else of the psychical life of childhood, or, if not forgotten, considered alnormal hecause of its future monstrous development. Such a reflex, it may be saicl, if normal, is congenital. This much is in strictness true. but an entirely clifferent aspect is given to the congenital theory. What is really pathological in this aberration is the extraordinary intensification of the sexual feelings and the unbridled lack of restraint witl which the subject indulges his senses and seeks every opportunity for gratification. These. without doubt, depend upon the neuropathic constitution. The contrast in this respect with normal hetero-sexual persons brings the difference into strong relief.

Finally, the fact must not be lost sight of-it is not questioned-that cultivation is capable of generating this aberration and developing it to its most intense degree. 
even to the feeling of repulsion for the opposite sex and to the acquisition of contrary tastes and habits. Acquired cases of this kind are recognized and illustrated by cases 94. 95. 96, 99, etc., of von Krafft-Elsing. It is not, then, a question of the sufficiency of this influence. The only question is. "ire all cases due to this influence, or are those cases in which there is no evidence in the histories, so far as obtained, of cultivation, and in which there is an apparent spontaneous origin, properly to be regarded as congenital?

One logical consequence of the cultivation theory has been overlooked, as it seems to me. by von SchrenckNotzing. It follows as a necessary corollary that this socalled perversion is not really a perversion. but a perversity -a vice rather than a disease.

From one standpoint the view may be modified. It has already been said that a habit may be so intensely cultivated as to become in time alnost automatic and independent of volitional control. The nervous processes involved may thus become shunted off from the rest of the psychical life as true psychoses. It is tenable that in some persons these aberrations may become by cultivation real imperative sensations and ideas. Though vice may be the roal traversed, the final stage may be disease.

Analogy with what takes place in other fields of the nervous system would make it intelligible that sexual feelings and actions may by constant repetition (cultivation) become associated together and developed into a sort of quasi-independent neural activities, which may then become practically inclependent of the will-or, in other words, a psychosis.

Sexual perversion, then, may, from the point of view of pathogenesis, be put in the same class with many of the manifestations of hysteria and other psycho-neuropathic states. The constant excitation of various bodily symptoms by the neurasthenic tends to cultivate them into inperative habits, which control his organism. The hysteric dwelling on certain ideas, whether they relate to 
herself or her environment, tends to nurture and cultivate them, till they may acquire such monstrous intensification that they control her psychical life.

From small beginnings it is possible that even most intense doubts and fears may be evolved by this cultivation, culminating, perhaps, in imperative irleas (insanity of (loubt, folie de toucher, etc.). By constant indulgence of her feelings-revelling in morbid introspection-giving herself up to egotistical debauches, self-pity and wrong inferences, the hysteric or neurasthenic cultivates her body and mind into becoming such 'a sensitive machine that she can no longer adapt herself to her environment, but must be removed to an institution. where her environment can be adapted to her; of course. I am drawing an extreme picture, but such extreme pictures exist.

Therapeutically, the point of view which we take of the genesis of these psychoses, sexual and non-sexual, is of extreme importance. If they are not the manifestations of a diseased nervous system, in the sense that they are the necessary expression of a diseased body, whether congenital or not, then there is no escape from therapentic hopelessness so long as the psychopathic state continues. But if psychoses of this kind are the result of cultivation. whether by the influence of external surroundings or by the subject's own conduct-cultivated into psychoses because the soil is a psychopathic one-then we may fairly hope by connter-education to replace the morbid processes by healthy ones. For myself, I believe that cultivation is the road by which many neurasthenics and hysterics reach the final goal of confirmed invalidism-cultivated sometimes by the patient herself, too often by the timid physician, who dares not speak the trith, or who fears to do harm. I do not believe in. and I am afraid I have no patience with the laisse $z$-faire system which contents itself with removing every source of external irritation and then -doing nothing. The neurasthenic will be more easily 
cured if she is isolated, but after this her treatment must be a process of education. The hysteric will do better if her environment is adapted to her weakness. but her education must then begin. I am aware that when the damage is too great nothing will avail-but we can always try. The physician is capable of doing the greatest goodbut he is also capable of doing the greatest harm-and no influence for harm is greater than that of the physician who unwittingly encourages corporeal symptoms by intimation of possible disease, danger and caution, or of psychical symptoms by a failure to combat fixed ideas. and to develop a sense of duty, self-control and right-mindedness. A harmful influence of this kind is multiplied a hundred fold by the unremitting kindness and attention and devotion of the physician himself.

Coming now to hard facts. the treatment of the sexual psychoses-if we can accept the statistics of von SchrenckNotzing-lias given results which contraclict the congenital. theory. Far from being hopeless, as the congenital theory would imply, the treatment of sexual paræsthesia is attended in a large proportion of cases with encouraging results. When the sexual aberration is only a part of great mental clegeneration. such as imbecility, dementia or paranoia, of course, any at tempt must be hopeless. But where the psychopathic basis is of a minor degree, and the intellect is not materially affected, it must appear. if we are to judge by reports of published cases, that improvement or cure may be accomplished. This, of course, presupposes that a person desires to be cured. It is highly improbable that a person can be cured against his will. and it is evident that many do not want to be cured. The chief and most effective therapeutic remedy has been hypnotic suggestion. In the hands of von Schrenck- Notzing and others this remerly has given decicledly favorable results. The total number of cases collected by von Schrenck-Notzing is 32 . The results of treatment were as follows: 
Failures....................... 5-15.025 per cent.

Sliglttly improved.................. 4-12.5 per cent.

Essentially improved, with later report.... I I-34.375 per cent.

Cured, so; without later report, $2 \ldots \ldots \ldots .12-37.5$ per cent.

100

Thus, about go per cent. were essentially improved or cured. The fact that of the 12 cures later reports were obtained. sometimes after considerable periods (four or five years) in ro makes these statistics of considerable value. Of the 32 patients, 5 were not amenable to hypnosis, 7 were cases of psycho-sexual hermaphroditism. 20 of contrary sexual instinct, 2 of sadism, 3 of masochism.

But, besides direct suggestion, other forms of mental therapentics should be employed for the purpose of strengthening the will power and developing the character of the patient.

To be brief, the methods of treatment and the results are the same as when dealing with other manifestations of neurasthenia, hysteria or degeneracy, when these are cultivated, as is more than frequently the case. For these, also, isolation is not enough, nor is the so-called rest cure or forced feedling. but education is essentialeducation in a broad sense--which includes the development of the common sense, the intelligence, the will, the moral sense and the luilding of the character of the individual.

Dr. William Hirsch submitted a paper entitled:

NOTES ON A CASE OF TRAUMATIC INJURY OF THE PNEUMOGASTRIC. HYPOGLOSSAL. AND SYMPATHETIC NERVES, as a candiclate's paper. It is published elsewhere.

Dr. H. M. Thomas submitted a paper entitled: PROGRESSIVE CENTRAL MUSCULAR ATROPHY; REPORT OF A CASE WITH AUTOPSY, as a canclidate's paper. It is published elsewhere. 